\title{
Early detection of cervical cancer with visual inspection methods: A summary of completed and on-going studies in India
}

\author{
R Sankaranarayanan, MD,(1) BM N ene, MD, (2) K D inshaw, MD, (3) R Rajkumar, MD, (4) S Shastri, MD, ${ }^{(3)}$ \\ R W esley, MD, ${ }^{(5)}$ P Basu, MD, ${ }^{(6)}$ R Sharma, MD, ${ }^{(7)}$ ST hara, MD ${ }^{(5)}$ A Budukh, ${ }^{(2)}$ DM Parkin, MD. ${ }^{(1)}$
}

\section{Sankaranarayanan R, Nene BM, Dinshaw K, Rajkumar R, Shastri S, Wesley R, Basu P, Sharma R,Thara S, Budukh A, Parkin DM. Early detection of cervical cancer with visual inspection methods:A summary of completed and on-going studies in India. Salud Publica Mex 2003;45 suppl 3:S399-S407. This paper is available too at: \\ http://www.insp.mx/salud/index.html}

\begin{abstract}
A bstract
India is a high-risk country for cervical cancer which accounts a quarter (126000 new cases, 71000 deaths around 2000 ) of the world burden.The age-standardized incidence rates range from 16-55 per 100000 women in different regions with particularly high rates in rural areas. Control of cer vical cancer by early detection and treatment is a priority of the $\mathrm{N}$ ational Cancer Control Programme of India. There are no organized cytology screening programmes in the country. The technical and financial constraints to organize cytology screening have encouraged the evaluation of visual inspection approaches as potential alternatives to cervical cytology in India. Four types of visual detection approaches for cervical neoplasia are investigated in India: a) naked eye inspection without acetic acid application, widely known as 'downstaging'; b) naked eye inspection after application of 3-5\% acetic acid (VIA); c) VIA using magnification devices (VIAM); d) visual inspection after the application of Lugol's iodine (VILI). Downstaging has been shown
\end{abstract}

\author{
Sankaranarayanan R, Nene BM, Dinshaw K, \\ Rajkumar R, Shastri S, Wesley R, Basu P, \\ Sharma R,Thara S, Budukh A, Parkin DM. \\ Detección oportuna de cáncer cervical \\ con métodos de inspección visual: \\ un resumen de estudios en India. \\ Salud Publica Mex 2003;45 supl 3:S399-S407. \\ Este artículo también está disponible en: \\ http://www.insp.mx/salud/index.html
}

\section{Resumen}

La India es un país de alto riesgo de cáncer cervical, donde se presentan cerca de la cuarta parte de los casos del total mundial (126000 casos incidentes y 71000 muertes durante 2000). La tasa de incidencia estandarizada por edad se encuentra en el rango de 16 a 55 por 100000 mujeres en diferentes regiones con tasas particularmente altas en áreas rurales. El control del cáncer cervical por detección temprana y tratamiento es una prioridad del Programa Nacional de Control de Cáncer y, desafortunadamente, no hay programas organizados de tamizaje citológico en este país. La infraestructura técnica y financiera para organizar tamizaje en este tipo de cáncer, ha promovido la inspección visual como una potencial alternativa de la citolo gía cervical en la India. Se investigan cuatro tipos de opciones de detección visual de neoplasia cervical: a) inspección a ojo desnudo sin la aplicación de ácido acético, opción ampliamente conocida como downstaging; b) inspección de ojo desnudo después de la aplicación de ácido acético de 3 a $5 \%$ (VIA); c) VIA usando un dispositivo de aumento (VIAM); d)

The funding assistance provided by the Bill and Melinda Gates Foundation through the Alliance for Cervical Cancer Prevention (ACCP) for the IARC cervical cancer prevention studies in India is gratefully acknowledged. We thank Mr G. Patwardhan, Additional Secretary of Health, Ministry of Health \& Family W elfare, Government of India, for his support.

(1) International A gency for Research on Cancer, 150 cours Albert Thomas, Lyon 69008, France.

(2) Nargis Dutt Memorial C ancer Hospital, A galgoan Road, Barshi 413401 , Solapur District, Maharashtra, India.

(3) Tata Memorial Centre, Dr Ernest Borges Road, Parel, Bombay 400 012, India.

(4) Christian Fellowship Community Health Centre,A mbillikai 624 612, Dindigul District, India.

(5) Regional Cancer Centre,Trivandrum 695011, India.

(6) Chittaranjan N ational Cancer Institute, 37 SP Mukherjee Road, Calcutta 700 026, India.

(7) Bhagwan Mahaveer Cancer Hospital \& Research Centre, Jawaharlal N ehru Marg, Jaipur 302 017, India. 
to be poorly sensitive and specific to detect cervical neo plasia and is no longer considered as a suitable screening test for cervical cancer.VIA,VIAM and VILI are currently being investigated in multicentre cross-sectional studies (without verification bias), in which cytology and HPV testing are also simultaneo usly evaluated, and the results of these investigations will be available in 2003. These studies will provide valuable information on the average, comparative test performances in detecting high-grade cervical cancer precursors and cancer. Results from pooled analysis of data from two completed studies indicated an approximate sensitivity of $93.4 \%$ and specificity of $85.1 \%$ for VIA to detect CIN 2 or worse lesions; the corresponding figures for cytology were $72.1 \%$ and $91.6 \%$. The efficacy of VIA in reducing incidence of and mortality from cervical cancer and its cost-effectiveness is currently being investigated in two cluster randomized controlled intervention trials in India. 0 ne of these studies is a 4-arm trial addressing the comparative efficacy of VIA, cytology and primary screening with HPV D N A testing. This trial will provide valuable information on comparative detection rates of CIN 2-3 lesions by the middle of 2003.The expected outcomes from the Indian studies will contribute valuable information for guiding the development of public health policies on cervical cancer prevention in countries with different levels of socio-economic and health services development and open up new avenues of research.This paper is available too at:http://www.insp.mx/ salud/index.htm

Key words: cervix neoplasms/control and prevention/ cytology; screening; India inspección visual después de la aplicación de yodo-lugol (VILI). Se ha mostrado que el Downstaging ha sido pobremente sensible y específico para detectar neoplasia cervical y no es considerado ampliamente como una prueba de tamizaje conveniente para cáncer cervical. VIA, VIAM y VILI son frecuentemente investigados en estudios de corte transversal multicéntricos (sin verificación de sesgo), en los que se evalúan simultáneamente la citología y las pruebas delVPH; Ios resultados de esas investigaciones estarán disponibles próximamente. Estos estudios proveerán información valiosa sobre el desarrollo de pruebas comparativas para detectar lesiones de alto grado precursoras de neoplasia cervical, y cáncer invasor. Los resultados de los análisis de los datos de dos estudios previos indicaron una sensibilidad aproximada de $93.4 \%$ y una especificidad de $85.1 \%$ paraVIA en la detección de CIN 2-3 0 lesiones invasoras, comparadas con las de citología con $72.1 \%$ y $91.6 \%$ de sensibilidad y especificidad, respectivamente. La eficacia deVIA para la reducción de la incidencia y la mortalidad de cáncer cervical y su costo-efectividad están siendo actualmente investigadas en dos ensayos de intervención aleatorizados controlados en población de la India. Uno de esos estudios es un ensayo con cuatro brazos que establece la eficacia comparativa de VIA, citología y tamizaje primario, con pruebas deADN delVPH.Este ensayo proveeráinformación valiosa so bre la detección comparativa de tasas de lesiones de CIN 2-3 que podrá ser utilizada para guiar el desarrollo de las políticas en salud pública sobre prevención del cáncer cervical en países con diferentes niveles socioeconómicos y abrir nuevos caminos de investigación. Este artículo también está disponible en: http://www.insp.mx/salud/index.html

Palabras clave: detección oportuna de cáncer; imagen visual cervical; cáncer cervical; India
A very high risk of cervical cancer is observed in India. The reported age-standardized incidence rate (ASR) of cervical cancer during 1993-1997 ranges from 11-30 per 100000 women in different regions of India. ${ }^{1}$ The incidence rates are particularly high in rural areas: ASR as high as 55/100 000. ${ }^{2}$ Though a slow and steady decline in cervical cancer incidence rates is observed in some urban populations, the rates are still high, particularly in rural areas, and the absolute number of cases is on the increase due to population growth. ${ }^{3}$ India accounts for a quarter (126 000 new cases, 71000 deaths around 2000) of the world burden of cervical cancer (471 000 new cases and 233000 deaths). ${ }^{4}$ Control of cervical cancer by early detection and treatment is one of the priorities of the National Cancer Control Programme of India. ${ }^{5}$ (NCCP). There are no organised or opportunistic cervical cytology screening programmes anywhere in the country. However, cytology services are available on demand in urban areas. National consultations on cervical cancer control have concurred that cytology based screening programmes are not feasible in India for many years to come in view of technical, financial and manpower constraints. ${ }^{6}$ In this context, approaches based on visual inspection, as potential alternatives to cervical cytology, have received great attention in India.

Four visual inspection based cervical neoplasia early detection approaches have been investigated in the past or currently being evaluated in India. These are: a) Naked eye visualization of the cervix without acetic acid application by health workers, widely known as 'downstaging' or 'unaided visual inspection (UVI)'. We prefer to use the term 'downstaging' to denote this approach; b) Naked eye visual inspection of the cervix after application of 3-5\% acetic acid (VIA); c) Visual inspection with acetic acid using magnification devices (VIAM); d) Visual inspection after the application of Lugol's iodine (VILI). A brief description of the Indian studies using these four approaches and their findings is provided in this paper. 


\section{'Downstaging' studies in India}

Downstaging has been defined as "the detection of the disease in an earlier stage when still curable, by nurses and other non-medical health workers using a speculum for visual inspection of the cervix". ${ }^{7}$ Downstaging was advocated for evaluation in areas where cytology screening would not be possible and where the majority of cases of carcinoma of the cervix are diagnosed in advanced stages. ${ }^{7}$ It was implied that improving therapeutic intervention by detecting early preclinical lesions might be useful in preventing deaths from cervical cancer.

There have been eight published studies of downstaging in India, carried out in Barshi, Delhi, Mumbai (Bombay), Kolkata (Calcutta) and Trivandrum. ${ }^{8-15}$ Seven of these studies allow estimation of test characteristics. ${ }^{9-15}$ However, six of the studies used cervical cytology as the 'reference investigation' or 'gold standard' to assess the test performance to detect cervical dysplasias and invasive cancer. ${ }^{9-14}$ The proportion of women subjected to colposcopy and histology was very low in these studies. A pooled analysis of data from these six studies indicates a sensitivity of $75.5 \%$ and a specificity of $82.0 \%$ to detect invasive cancer. Three studies permit the test characteristics to detect CIN 2 or worse lesions: a sensitivity of $75.5 \%$ and a specificity of $48.8 \% .{ }^{11,12,14}$ Cytology is not a diagnostic test and its sensitivity to detect cervical neoplasia varies considerably. ${ }^{16,17}$ The findings and deficiencies of the Indian studies using cytology as reference investigation have been extensively reviewed. ${ }^{15,18}$

Of particular interest in assessing the performance of downstaging is a recently reported cross-sectional study from Calcutta, India, in which 6399 women aged 30 to 64 years were screened with downstaging by trained workers. ${ }^{15}$ Two thresholds were used to define positive downstaging: 'low threshold' when any visible abnormality on the cervix was considered positive and 'high threshold' when selected abnormalities such as bleeding on touch, bleeding erosion, hypertrophied oedematous cervix, congested stippled cervix and growth or ulcer constituted the positive test. All women had colposcopy and biopsies were directed when colposcopy revealed abnormal lesions. True disease status was defined as histologically proved CIN 2 and worse lesions. Since all the participants received a diagnostic investigation (biopsy and/or colposcopy), sensitivity, specificity and predictive values were estimated directly. Low- and high-threshold downstaging were positive in $1585(24.8 \%)$ and 460 (7.2\%) women, respectively. The sensitivities of low- and high-threshold downstaging to detect high-grade precursors and invasive cancers were $48.9 \%$ and $31.9 \%$ respectively. The specificities were $75.8 \%$ and $93.3 \%$, respectively.

The results from the Indian studies of 'downstaging' indicate that it is not suitable as an independent primary screening modality for cervical neoplasia and should not be considered for early detection. It was often argued that downstaging was intended only for detection of early stage disease to achieve a stage shift in diagnosis in order to decrease morbidity and mortality from cervical cancer. Since downstaging involves investigation of a large number of screen positive women, it may prove to be a costly way of achieving a stage shift. The currently available evidence suggests that a shift towards early stages may be at achieved at considerably lower costs by health education and improved awareness, as revealed by the findings from Sweden and Barshi, India. ${ }^{19,20}$ In any case, in many low-resource countries with a high incidence of cervical cancer, where a low technology test might be considered for screening (e.g. countries in sub Saharan Africa), facilities for treating invasive cancer are inadequate. In this context, an early detection test with a potential to detect high-grade cervical cancer precursors is advisable. 'Downstaging' is not considered as a promising or experimental early detection approach in the most recent WHO document on national cancer control programmes. ${ }^{21}$

\section{Visual inspection with acetic acid (VIA) studies}

\section{Cross-sectional studies}

VIA is considered to be a promising approach in the detection of cervical neoplasia. ${ }^{21}$ VIA involves the application of 3-5\% dilute acetic acid on the cervix and the detection of opaque acetowhite area(s) close to the squamocolumnar junction constitutes a positive test outcome. Two previously reported cross-sectional studies simultaneously evaluated the test characteristics of VIA and cytology. ${ }^{22,23}$ However, these studies suffered from verification bias, as the reference investigations coloposcopy with or without biopsy were provided to screen positive women and to a selected proportion of screen negative women only. Thus sensitivity and specificity could not be estimated directly. Pooled analysis of data from these two indicated an approximate sensitivity of $93.4 \%$ and specificity of $85.1 \%$ for VIA to detect CIN 2 or worse lesions; the correspond- 
ing figures for cytology were $72.1 \%$ and $91.6 \%$. Thus VIA was found to be more sensitive but less specific than cytology.

Currently cross-sectional studies have been organized in four locations (Bombay, Calcutta, Jaipur and Trivandrum) to study the test characteristics of VIA on a large sample (30 000 women aged 30-59 years). Twenty three thousand women have already been recruited into these studies. These studies have been approved by the ethical committees of the collaborating national institutions and the International Agency for Research on Cancer (IARC). The study design is shown in Figure 1. The test characteristics of cytology (in four study locations), HPV DNA testing with HC II method (in three study locations), and visual inspection after the application of Lugol's iodine (VILI) (in four study locations) are simultaneously evaluated in these studies. All the participating women in these studies are investigated with colposcopy and directed biopsy depending upon the colposcopy findings (irrespective of the screening test outcomes) to establish the final disease status and these investigations constitute the reference investigation in this study population. Thus, these studies do not suffer from verification bias, as both screen negative and screen positive women receive the reference investigation. The data from the above studies will be pooled for establishing the comparative average test performance of VIA and the other screening tests in devetecting CIN 2 and advanced lesions. Results of pooled analysis will be available at the end of 2003.

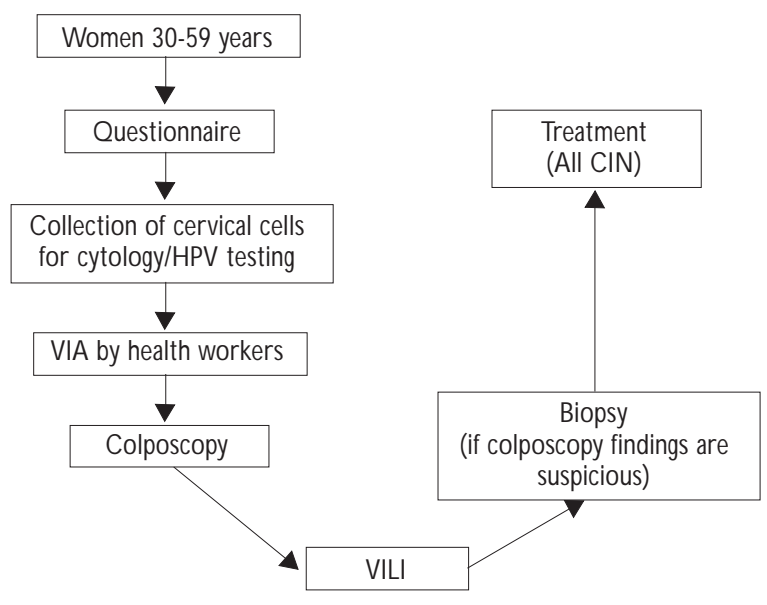

Figure 1. Design of CRoss-sectional studies of CerVICAL CANCER SCREENING, INDIA

\section{Randomized intervention trials}

Though there is currently a large body of data on the test accuracy of VIA, the efficacy and cost effectiveness of VIA based screening programme in reducing incidence of and mortality from cervical cancer is not known. This is being addressed in two cluster-randomised controlled intervention trials in India, which have been initiated in 2000. The design of these studies will be briefly described.

\section{Osmanabad district randomized cervical cancer screening} trial

The comparative efficacy and cost-effectiveness of once a life-time VIA (provided by nurses), conventional cytology, and HPV testing in detecting cervical neoplasia and in reducing incidence of and mortality from cervical cancer is evaluated in a four-arm cluster randomized, controlled intervention trial in Osmanabad district, Maharashtra, India. This is a joint collaborative study of the Nargis Dutt Memorial Cancer Hospital, Barshi; Tata Memorial Centre (TMC), Bombay; and the International Agency for Research on Cancer (IARC), Lyon, France. This study has been approved by the institutional ethical and scientific review committees of TMC, Bombay and the IARC.

Osmanabad district, is an industrially and economically backward district in India, located $450 \mathrm{~km}$ south east of Mumbai, in the state of Maharashtra, Western India. The literacy rate in adult women is around $20 \%$. Five hundred two villages in this district have been grouped under 52 clusters. Apparently healthy women aged 30-59 years and with intact uterus in these clusters have been randomly allocated to one of the four study groups and are invited to be screened once in a life-time with one of the tests (Figure 2).

Women in 125 villages in 13 clusters have been randomized to group 1 to be screened with VIA by nurses (VIA screening group); women in 124 villages in 13 clusters have been randomized to group 2, to be screened with cervical cytology (cytology screening group); women in 125 villages in 13 clusters are allocated to group 3 to be screened with HPV testing using HC II technique (HPV screening group); and women in 128 villages in 13 clusters are allocated to group 4 (control group) who receive the usual care prevailing in the district and receive person to person health education on the risk factors, methods of prevention and early detection for cervical cancer and are advised on the diagnostic and treatment facilities for 


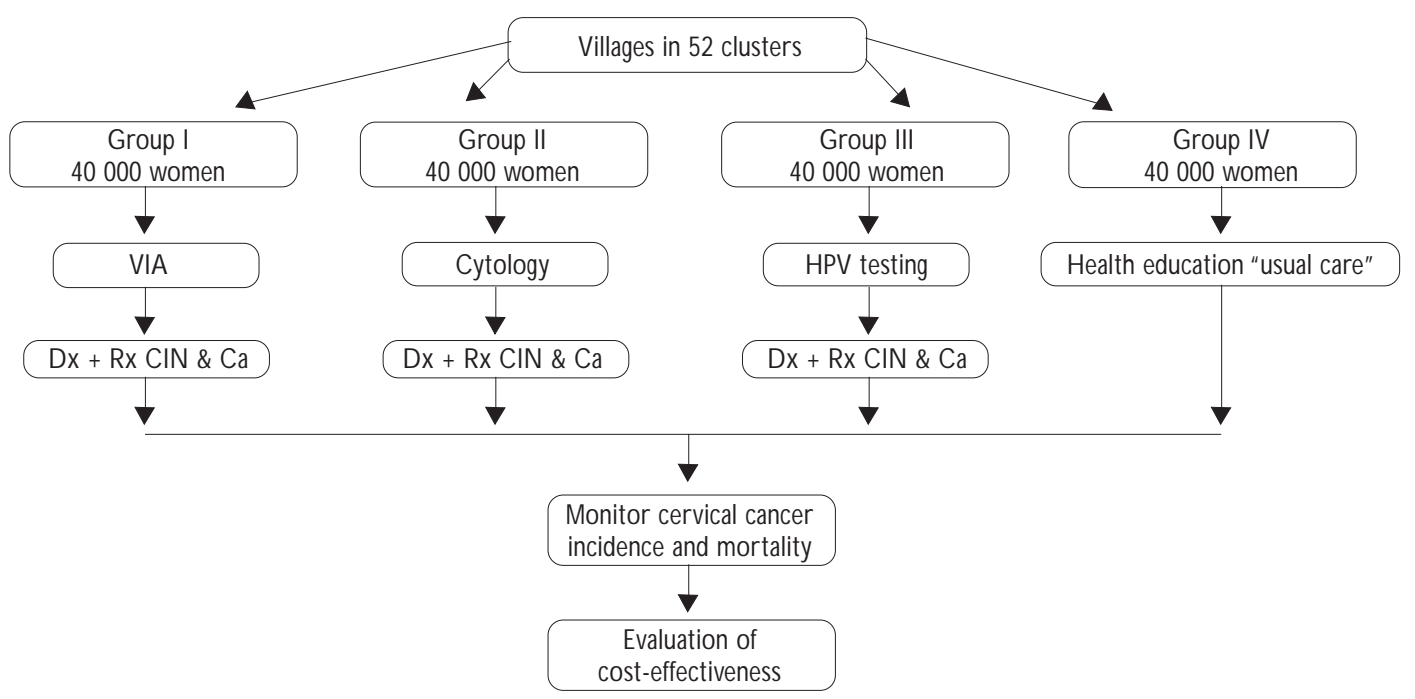

Figure 2. Design of Osmanabad district Randomized cervical Cancer screening trial, India

cervical neoplasia available in the district. The number of eligible women in each study group is estimated to be around 40000 .

Women randomized to groups 1-3 are personally invited for screening with specific tests in screening clinics conducted in primary health centres, or in make shift screening clinics organized in schools, women's club buildings, or the municipal buildings in the villages.

In group 1 , screening is carried out by applying $5 \%$ acetic acid and the findings are scored after one minute. Screen positivity is defined by the presence of opaque acetowhite area(s) close to or touching the squamocolumnar junction in the transformation zone. Cytology smears from women in group 2 are taken by nurses, which are processed and reported by trained cytotechnologists in the cytology laboratory of the project located in Barshi town. The results of cytology are reported using the Bethesda system (TBS) reporting categories. Those with atypical squamous cells of uncertain significance (ASCUS), atypical glandular cells of uncertain significance (AGUS), low-grade squamous intraepithelial lesions (LSIL), high-grade squamous intraepithelial lesions (HSIL), cervical glandular intraepithelial neoplasia (CGIN) and invasive carcinoma on cytology are considered screen positive. Cervical cells are collected from women in group 3 using the Digene HC II collection tubes and transported to the project HPV testing laboratory located in the project office in Barshi for testing and reporting. Those detected with more than 6000 viral DNA (> 1 RLU) copies are designated as screen positive in this group.

All screen positive women are investigated with colposcopy by trained doctors. Directed biopsies are carried out in women with colposcopically suspect neoplastic lesions. Biopsy specimens are processed in the project histopathology laboratory at Barshi and results are reported using the cervical intraepithelial neoplasia (CIN) terminology.

In order to avoid another recall for treatment of precancerous lesions and to maximize compliance to treatment, treatment decisions are made and carried out in the same session as colposcopy, based on colposcopic diagnosis, whenever possible. All grades of CIN are treated. Cryotherapy is provided to women with ectocervical CIN lesions involving less than $75 \%$ of the transformation zone, and that can be covered with the largest cryotherapy probe tip, without extension to the endocervix and vagina and without clinical evidence of invasion. Cryotherapy is provided only after directing a biopsy. Those with preinvasive lesions involving more than $75 \%$ of the transformation zone or those with lesions extending in to the cervical canal are treated with loop electrosurgical excision (LEEP) or cold knife conization. Cryotherapy is provided by nurses and LEEP by doctors. Those with invasive cancers are referred for treatment surgery and/or radiotherapy.

Women treated for preinvasive lesions are recalled at three months to assess if there is any evidence of 
local infection and if the wound has healed and for any immediate complications. They are assessed at one year from treatment for assessing treatment success and complications

The input and outcome measures used for evaluating this study are given in Table I. The entire district is covered by a population-based cancer registry, which will provide cervical cancer incidence data for the district. Mortality data will be obtained by active collection of data from the municipal death registers supplemented by periodic house-to-house surveys.

As of 31 June 2002, around 60000 women have been invited and $79 \%$ of the invited have been screened. Test positivity rates of VIA, cytology and HPV testing among the screened women were $16.4 \%, 9.5 \%$ and $11.4 \%$ respectively. Recruitment of women in this programme will be completed by mid 2003 and the final results for the various input measures, test positivity rates, detection rates of CIN 2-3 lesions, stage distribution of cervical cancers, 2-year survival rates, and case-fatality rates in the different study groups will be reported by the end of 2003.

\section{Dindigul district randomized cervical cancer screening trial}

A two-arm cluster randomized, controlled intervention trial has been initiated in 2000 to investigate the efficacy and cost-effectiveness of VIA (provided by nurses) in reducing incidence of and mortality from cervical cancer in Dindigul district, Tamil Nadu, India. This is a joint collaborative project between the Christian Fellowship Community Health Centre (CFCHC), Ambillikai, Dindigul district and the International Agency for Research on Cancer (IARC), Lyon, France. This study has been approved by the institutional review committees of the CFCHC and the IARC.

This programme involves 73000 apparently healthy women, with intact uterus, aged $30-59$ years living in 113 village panchayaths. Thirty eight thousad women in 57 village panchayaths have been rand- omized to be screened with once in a life-time VIA by nurses (VIA screening group); 35000 women in 56 village panchayaths have been randomly allocated to the control group, who receive the usual care prevailing in the district and receive person to person health education on the risk factors, methods of prevention and early detection for cervical cancer and are advised on the diagnostic and treatment facilities (Figure 3).

Women randomized to the VIA screening group are personally invited for testing in screening clinics conducted in primary health centres, or in make shift screening clinics organized in schools, women's club buildings, or the municipal buildings in the villages. VIA screening is carried out by applying $5 \%$ acetic acid and the findings are scored after one minute. Screen positivity is defined by the presence of opaque aceto white area(s) close to or touching the squamocolumnar junction in the transformation zone. All screen positive women are investigated with colposcopy by trained nurses. Directed biopsies are carried out in

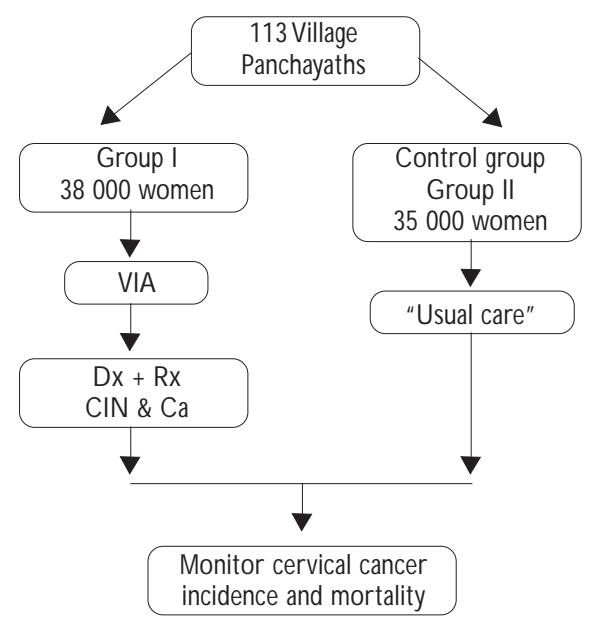

Figure 3. Design of Dindigul district randomized CERVICAL CANCER SCREENING TRIAL, INDIA

Table I

INPUT AND OUTCOME MEASURES IN RANDOMIZED TRIALS OF CERVICAL CANCER SCREENING IN INDIA

Input measures

- Number of invited women

- \% of invited women screened (participation rate)

- Compliance rate (\%) of screen positive women for colposcopy

- Biopsy rate (\%)

- Compliance rate for treatment (\%)

- Compliance rate (\%) for follow-up
Intermediate end-points

- Test positivity rate (\%)

- Programme sensitivity (\%)

- Stage distribution of cervical cancer

- 2-and 5-year survival rate (\%)

- Case-fatality rate (\%)
Final end points

- Detection rate of CIN 2-3 lesions

- Incidence rate (per 100 000) of cervical cancer

- Mortality rate (per 100 000) from cervical cancer

- Cost-effectiveness indices 
women with colposcopically suspect neoplastic lesions. Biopsy specimens are processed in the project histopathology laboratory and results are reported using the cervical intraepithelial neoplasia (CIN) terminology.

As of 31 June, 30000 women have been invited and $65 \%$ of those invited have been screened. Test positivity rate of VIA, in the screened women was $11.2 \%$. Recruitment of women in this programme will be completed by the end of 2002 and the final results for input measures (Table I) and outcome measures such as test positivity rate, detection rate of CIN 2-3 lesions, stage distribution of cervical cancer, 2-year survival and case fatality rates will be reported in early 2003.

Information on the comparative trends in incidence/mortality, incidence and mortality rate ratios following the introduction of the screening interventions in the above two randomized trials is expected to emerge around 2007.

\section{Studies on visual inspection with acetic acid after} magnification (VIAM)

Since several reported studies indicate a significantly lower specificity for VIA when compared to cytology, simple magnifying devices $(2 X-4 X)$ have been used to visualize the cervix after application of acetic acid to find out if this approach may improve specificity of VIA without compromising sensitivity. In a hospitalbased cross-sectional study in Delhi involving 406 women, Parashari and coworkers, ${ }^{24}$ reported a sensitivity of $88.1 \%$ and specificity of $67.5 \%$ for VIAM using a $2.5 \mathrm{X}$ magnifying device for reporting. It is of interest to note that the specificity falls within the range observed for VIA in other studies. We have completed a cross-sectional study in Calcutta, India, which has evaluated the comparative accuracy of VIA and VIAM in 6000 women and the results will be reported soon. Incidentally, no differences in test characteristics between VIA and VIAM were observed in a reported cross-sectional study in South Africa. ${ }^{25}$

\section{Studies on visual inspection with Lugol's iodine (VILI)}

VILI is similar in approach to the Schiller iodine test of the 1930s, which relied on viewing the cervix with the naked eye after application of iodine solution to identify yellow iodine non-uptake areas on the cervix. The practice of the test was discontinued after the introduction of cytology, in view of its non-specific nature, and relatively common false positive results. Lugol's iodine solution is prepared by dissolving $5 \mathrm{gm}$ of iodine and $10 \mathrm{gm}$ of potassium iodide in $100 \mathrm{ml}$ distilled water. VILI findings depend on the interaction between iodine and glycogen. Normal, mature, squamous epithelium is characterized by an abundance of glycogen, whereas abnormal epithelium contains relatively little or no glycogen. Therefore, application of iodine solution to normal squamous epithelial cells will produce a dark mahogany brown, or almost black stain, while columnar and abnormal epithelial cells, as well as immature metaplasia, all of which contain little or no glycogen, remain relatively unstained, showing areas that are colourless, pale, or mustard-yellow in colour.

However, the increasing use of colposcopy as a diagnostic triage investigation, in which iodine application was used by many colposcopists, particularly to delineate the lesions, has helped in recognizing and discriminating the findings that may lead to false positive results after iodine application. We have observed, in a pilot study, that health workers found it easier to detect the colour patterns produced by iodine staining, rather than acetic acid, we decided to re-evaluate the accuracy VILI as a screening test to detect cervical neoplasia, in cross-sectional studies in four locations in India (Figure 2). These studies, when completed, will have 25000 women tested with VILI.

We have prepared an atlas depicting the staining patterns associated with normal cervix, ectropion, polyps, inflammatory conditions and squamous metaplasia, and neoplastic conditions, in order to reduce the frequency of false positive outcomes. The naked eye visual findings after iodine application is reported as negative and positive, as follows.

VILI finding is scored 'negative' when one or more of the following findings are observed: the entire area of the cervix outside the SCJ was stained brown by iodine; or when the endocervical columnar epithelium was the only iodine non-staining area in the cervix; or when the endocervical columnar epithelium was the only iodine non-staining area in the cervix or when there was "leopard skin" appearance suggestive of Trichomonas vaginalis infection, or when there were scattered pepper-like iodine negative pale or colourless areas in the squamous epithelium or scattered, irregular, streak-like iodine negative pale areas; or when pale or yellow iodine non-uptake areas far away from the cervical os and dissociated from the SCJ were present. VILI is categorized 'positive' when saffron or mustard-yellow iodine non-uptake lesions are observed close to the squamocolumnar junction.

There are no published results of VILI yet. Our current studies in India have recruited around 18000 women and the test positivity in different studies vary between $18-28 \%$. The final results will be reported in late 2003. 


\section{Training and quality control}

The health workers providing VIA, VIAM, and VILI in the Indian studies have been trained in 5-day training courses, using the IARC training manual on VIA and VILI. ${ }^{26}$ The training courses involve theoretical lessons for eight hours dealing with anatomy and physiology of the female genital tract, pathology of cervical neoplasia and method of speculum examination, VIA and VILI. This is followed by clinical sessions involving 100-150 women as subjects for the trainees over four days when the practical aspects of testing, reporting, investigations and treatment are taught.

There are no standard methods of quality control for visual inspection-based screening tests. In the context of the Indian studies we have used studies of agreement between the health workers and master trainers, on the findings of randomly selected photographs of cervix after application of acetic acid or iodine, for quality control. The findings and sensitivity of VIA provided by health workers are closely monitored and periodic short retraining sessions are organized.

\section{Conclusion}

The Indian studies have clearly established the unsatisfactory test characteristics of 'downstaging' and its role as a less promising test for cervical cancer prevention. The answers for some of the important research issues concerned with other visual inspection-based screening tests such as VIA, VIAM and VILI may emerge when the currently on-going Indian studies are completed and analysed. There will be more valid information on the performance of the above tests in detecting lesions. The value of screening with combinations of tests is likely to be better defined. The randomized trials will provide the much-needed information on the extent of incidence and mortality reduction associated with VIA screening and its cost effectiveness in comparison to screening with cytology and HPV testing. The long-term impact of over treatment associated with VIA may be well defined. They will also provide useful information on feasible models of delivery of cervical cancer prevention services in low-resource countries. Thus the expected outcomes from these studies will provide valuable information for guiding the development of public health policies on cervical cancer prevention in countries with different levels of socio-economic and health services development and open up new avenues of research.

\section{References}

1. Parkin D M, W helan SL, Ferlay J, Raymond L,Young J, ed. C ancer incidence in five continents. IARC 1997;Scientific Publication N 0.143 Vol.VII.

2. Rajkumar R, Sankaranarayanan R, Esmi A, Jayaraman R, C herian J, Parkin D M. Leads to cancer control based on cancer patterns in a rural population in South India. Cancer Causes Control 2000;11:433-439.

3. Sankaranarayanan R, Budukh A M, Rajkumar R.Effective screening programmes for cervical cancer in low- and middle-income developing countries. Bull W orld Health O rgan 2001;79:954-962.

4. Ferlay J, Bray F, Pisani P, Parkin D M. G LO BO CAN 2000: Cancer incidence, mortality and prevalence worldwide. IARC Press, 2001; Version 1.0. IARC CancerBase N 0.5 .

5. Ministry of Health and Family W elfare. $N$ ational Cancer Control Programme of India. N ew D elhi: G overnment of India, 1982. 6. Institute of Cytology and Preventive 0 ncology (ICMR). $N$ ational workshop on control of cervical cancer-alternative strategies. N ew Delhi, India: 2001.

7. Stjernsward J, Eddy D, Luthra U, Stanley K. Plotting a new course for cervical cancer screening in developing countries. World Health Forum 1987;8:42-45.

8. Sehgal A, Singh V, Bhambhani S, Luthra UK. Screening for cervical cancer by direct inspection. Lancet 1991;338:282.

9. Singh V, Sehgal A, Luthra UK. Screening for cervical cancer by direct inspection. Brit Med J 1992;304:534-535.

10. BharghavaVL,Verma K, Sharma R, Batra S, A nandalakshmy PN .A Hospital-based study on the use of paramedical personnel for clinical down-staging of cancer cervix. Indian J Med Res 1993;98:65-68. 11. Sujathan K, Kannan S, Pillai KR, Mathew A, Joseph M, Shyamalakumari $B$ et al. Implications of gynaecological abnormalities in pre-selection criteria for cervical cancer screening: Preliminary evaluation of 3602 subjects in south India. Cytopathology 1995;6:75-87.

12. Rao SR, Revathy S, Malvi SG, Taskar V, Rao RS. Pitfalls in the visual inspection of the cervix, as a method of downstaging cancer of the cervix in developing countries. Indian J 0 bstet Gynaecol 1995;28:659-665.

13. N ene BM, D eshpande S, Jayant K, Budukh AM, D ale PS, D eshpande $D A$ et al. Early detection of cervical cancer by visual inspection: A population-based study in rural India. Int J C ancer 1996;68:770-773. 14. W esley R, Sankaranarayanan R, Mathew B, Chandralekha B, Beegum $A A, A m m a N S$ et al. Evaluation of visual inspection as a screening test for cervical cancer. Br J Cancer 1997;75: 436-440.

15. Basu P, Sankaranarayanan R, Mandal R, Roy C, D as P, Choudhary D et al. Evaluation of downstaging in the detection of cervical neoplasia in Kolkata, India. Int J C ancer 2002;100:92-96.

16. Fahey MT, Irwig L, Macaskill P. Meta-analysis of Pap test Accuracy. Am J Epidemiol 1995;141:680-689.

17. N anda K, MCC rory DC , Myers ER, Bastian LA, Hasselblad V, Hickey JD et al.Accuracy of the Papanicolaou test in screening for and followup of cervical cytologic abnormalities:A systematic review. Ann Intern Med 2000;132:810-819.

18. Sankaranarayanan R, Syamalakumari B,W esley R, Thara Somanathan, Chandralekha B, Sreedevi Amma N et al.Visual inspection as a screening test for cervical cancer control in developing countries. In: Franco E, Monsonego J, ed. $\mathrm{N}$ ew developments in cervical cancer screening and prevention. O xford: Blackwell Science, 1997:411-421.

19. Ponten J,A dami HO , Bergstorm R, D illner J, Friberg LG, Gustafsson L et al. Strategies for control of cervical cancer. Int J Cancer 1995;60:1-26. 
20. Jayant $K, R a 0 R S, N$ ene BM, D ale PS. Improved stage at diagnosis of cervical cancer awareness in a rural population. Int J Cancer 1995;63: 161-163.

21. W orld Health $O$ rganization. N ational $C$ ancer C ontrol Programmes. Policies and managerial guidelines. Second Edition. Ginebra: 2002. 22. Sankaranarayanan R,W esley R, Somanathan T, D hakad N, Shyamalakumary B, Sreedevi A mma N et al. Performance of visual inspection after acetic acid application (VIA) in the detection of cervical cancer precursors. Cancer 1998:83:2150-2156.

23. Sankaranarayanan R, Shyamalakumary B, W esley R, Sreedevi A mma $N$, Parkin D M, Krishnan N air M.Visual inspection with acetic acid in the early detection of cervical cancer and precursors. Int ] C ancer 1999:80:161-163.

24. Parashari A, Singh V, Seghal A, Satyanarayana L, So dhani P, G upta MM. Low-cost technology for screening uterine cervical cancer. Bull W orld Health 0 rgan 2000;78:964-967.

25. Denny L, Kuhn L, Pollack A, W right TC Jr. Direct visual inspection for cervical cancer screening:An analysis of factors influencing test performance. Cancer 2002;94:1699-1707.

26. Sankaranarayanan R,W esley R.A practical manual on visual screening for cervical neoplasia. IARC Internal Technical Manual. Lyon: IARC, 1999. 